\title{
RELAÇÃO ENTRE LINGUAGEM VERBAL E NÃO VERBAL EM UM LIVRO DIDÁTICO DE LÍNGUA INGLESA
}

(The relationship between verbal and non verbal language in an English language text book)

Ariane Escobar Rossi ${ }^{1}$

(Universidade de Santa Maria)

\begin{abstract}
This work investigates the interpersonal, ideational and textual meanings present in the non verbal language of an introductory page from a textbook's unit and its relation to the verbal language. The images were numbered and classified according to categories from visual grammar (KRESS; van LEEUWEN, 2006). The results indicate that the relationship between non verbal and verbal modes has the purpose of calling students' attention and anticipating the unit's theme. Verbal language seems ambiguous in relation to the non verbal one, once we do not know if it is English for all ethnicities or suggests a pattern to be learnt which leads us to think there is an ideological point of view concerning the English language that is thought.
\end{abstract}

Keywords: Multimodality. Textbook. Verbal and non verbal language.

\section{RESUMO}

Este trabalho investiga os significados interpessoal, ideacional e textual na linguagem não verbal da página introdutória da unidade de um livro didático $(L D)$ relacionando-a com a linguagem verbal. As imagens foram numeradas e classificadas conforme as categorias da gramática visual de Kress e van Leeuwen (2006). Os resultados mostram que a relação entre os modos verbal e não verbal tem o propósito de chamar a atenção do aluno e antecipar o assunto que será discutido. A linguagem verbal parece ambígua em relação a não verbal, pois não sabemos se é um inglês para todas as etnias ou se sugere um padrão de língua, o que nos leva a crer que há uma visão ideológica em relação à língua inglesa ensinada.

Palavras-Chave: Multimodalidade. Livro didático. Linguagem verbal e não verbal.

\section{INTRODUÇÃO}

Não é de hoje que a relação entre linguagem verbal e não verbal tem conquistado um amplo destaque nos estudos multimodais, principalmente com o surgimento da gramática visual, proposta pelos teóricos Gunther Kress and Theo van Leeuwen (2006). Essa obra investiga o significado das estruturas visuais, apontando para interpretações particulares da experiência, uma vez que os modos de representação semiótica variam de uma cultura específica para outra (KRESS; van LEEUWEN, 2006, p. 2). Motta-Roth e Hendges (2010, p. 44) destacam a importância de estudarmos a ampla gama de modos semióticos que são

\footnotetext{
${ }^{1}$ Secretária Executiva Bilíngue na Secretaria de Apoio Internacional - SAI/UFSM e Doutoranda do Programa de Pós-Graduação em Letras - PPGL/UFSM. É licenciada em Letras Inglês e Literaturas da Língua Inglesa pela Universidade Federal de Santa Maria - UFSM (2007), Especialista em Metodologias de Ensino de Língua Inglesa pelo Centro Universitário Franciscano - UNIFRA (2010) e Mestre em Letras - Estudos Linguísticos pela UFSM (2012).
} 
empregados na comunicação contemporânea a fim de que nos possamos engajar na atual sociedade cada vez mais globalizada em que estamos inseridos.

Além disso, destaca-se a importância de enfatizar os significados de imagens em materiais didáticos que passaram a ter uma proporção cada vez maior de representações visuais, apresentando imagem e escrita em posições igualitárias (KRESS, 2010, p. 143). Tendo como referência o contexto de ensino/aprendizagem de inglês como língua estrangeira (ILE), procuro investigar, neste artigo, os significados interpessoal, ideacional e textual de imagens, os relacionado à linguagem verbal. Para tanto, analiso a página introdutória da unidade de um Livro Didático (LD), volume 1, da coleção Prime. Essa coleção tem como foco o ensino de inglês para o ensino médio e foi aprovada pelo Programa Nacional do Livro Didático $^{2}$ (PNLD) 2012, que oferece materiais didáticos com unidades, utilizando diferentes gêneros de popularização da ciência (PC) como objeto de análise e de ensino da linguagem. A página introdutória de cada unidade, uma das quais constitui o objeto de análise dessa pesquisa, tem a função de apresentar o conteúdo a ser explorado na unidade.

Em relação ao gênero LD e o papel das imagens no cotidiano dos alunos, Kress e van Leeuwen (2006, p.16) são críticos ao afirmarem que:

Fora da escola, entretanto, as imagens desempenham um papel cada vez mais significativo, e não somente em textos para crianças. Seja na mídia impressa ou eletrônica, jornais, revistas, CD-ROMs, websites, seja como materiais de relações públicas, anúncios ou como materiais de informação de todos os tipos, a maioria dos textos da atualidade envolvem uma complexa combinação de textos escritos, imagens, e outros elementos gráficos ou sonoros, produzidos como entidades coerentes (muitas vezes visual num primeiro nível em vez de verbal) por meio do layout. Mas a habilidade de produzir textos multimodais desse tipo, embora seu papel seja fundamental na sociedade contemporânea, não é ensinada na escola (tradução minha). ${ }^{3}$

O que os autores procuram argumentar é o fato de não presenciarmos em nossas escolas um currículo que dê conta dos vários modos semióticos que estão envolvidos, de uma

\footnotetext{
${ }^{2}$ O Programa Nacional do Livro Didático (PNLD) é o mais antigo dos programas voltados à distribuição de obras didáticas aos estudantes da rede pública de ensino brasileira e iniciou-se, com outra denominação, em 1929. Ao longo desses quase 70 anos, o programa se aperfeiçoou e teve diferentes nomes e formas de execução. O PNLD é voltado para o ensino fundamental público, incluindo as classes de alfabetização infantil.

3 "Outside school, however, images play an ever-increasing role, and not just in texts for children. Whether in the print or electronic media, whether in newspaper, magazines, CD-ROMs or websites, whether as public relations materials, advertisements or as informational materials of all kinds most texts now involve a complex interplay of written text, images, and other graphic or sound elements, designed as coherent (often at the first level visual rather than verbal) entities by means of layout. But the skill of producing multimodal texts of this kind, however central its role in contemporary society is not taught in school". (KRESS; VAN LEEUWEN, 2006, p.16)
} 
maneira ou de outra, na rotina dos alunos. Uma das razões para essa lacuna pode ser conferida à resistência de professores, instituições de ensino e pais no que se refere aos métodos avaliativos das habilidades multissemióticas, pois não é comum que elas sejam cobradas dos alunos em exames, como vestibular e outros tipos de concursos. Kress (2010, p.182) aponta para uma visão multimodal (sócio-semiótica) de significados e aprendizagem, já que todos os modos de representar um significado devem ser valorizados, sejam eles escritos ou visuais.

Primeiramente, discutirei alguns aspectos teóricos pertinentes para que se compreenda a análise dos significados interpessoal, ideacional e textual, segundo a gramática visual de Kress e van Leuween (2006). Em seguida, serão apresentados os resultados que evidenciam a relação entre linguagem verbal (título da unidade) e não verbal (imagens da página). Por um lado a disposição das imagens sugere uma visão ideológica em relação ao ensino de uma língua inglesa padrão. Por outro lado, elas têm o papel de despertar a curiosidade do aluno a respeito dos temas que serão tratados na unidade, antecipando o assunto e acionando o conhecimento prévio dos leitores.

\section{AS METAFUNÇÕES NA GRAMÁTICA VISUAL}

Para que a teoria da semiótica social pudesse ser reconhecida como um sistema de comunicação de modos semióticos, Kress e van Leuween adaptaram as metafunções propostas por Michael Halliday (1984) que se aplicam a todos esses modos, não restringindose ao escrito e ao falado (KRESS; van LEUWEEN, 2006, p. 41-42). A metafunção ideacional refere-se a uma atividade humana pertinente e à capacidade da linguagem de representá-la, também conhecida como campo. A metafunção interpessoal diz respeito aos participantes dessa atividade, as relações entre eles e a capacidade da linguagem de constituí-la, também chamada de relações. Já a metafunção textual se concentra no papel desempenhado pela linguagem e a capacidade dela se organizar em um todo significativo, e pode ser definida como modo (MOTTA-ROTH, 2006, p.149).

Os significados ideacionais da gramática visual são concebidos pelas representações narrativas e conceituais, enquanto que os significados interpessoais são semelhantes às representações de interação com o expectador e a modalidade das imagens e os significados textuais são representados pela composição das figuras. Nesta análise discutirei os significados interpessoal, textual e ideacional, com destaque para o processo simbólico. 


\subsection{Significados ideacionais: representações narrativas e conceituais}

O significado ideacional da gramática visual pressupõe que um modo semiótico pode representar aspectos do mundo como ele é experienciado pelo homem. Esses objetos podem ser representados em um processo de interação o que se torna visível por meio de vetores, ou ainda podem estar relacionados em termos de classificação (KRESS; van LEUWEEN, 2006, p.42).

Os padrões visuais dos significados ideacionais podem ser divididos em dois tipos de estruturas: representações narrativas e representações conceituais. A primeira é semelhante à estrutura de uma sentença, pois descreve a imagem como se houvesse um sujeito, um verbo e um objeto. Na gramática visual eles serão respectivamente participante, processo e participante e/ou circunstâncias e são divididos em processos de ação, reação, mentais, verbais, de conversão, simbolismo geométrico e circunstâncias (MOTTA-ROTH; NASCIMENTO, 2009, p. 323).

No segundo tipo de representação, o conceitual, os participantes da imagem são representados na sua essência generalizada, ou seja, um conceito estático, pois não há vetores que indicam ação. As representações conceituais são divididas em: classificatórias, simbólicas e analíticas (com suas respectivas subcategorias).

No significado ideacional o participante representado (PR) realiza ações ou simplesmente é descrito em sua essência. Já em outro tipo de representação, a interpessoal, ele interage com o expectador, tem relações de poder, maior ou menor proximidade com esse expectador, como veremos a seguir.

\subsection{Significados interpessoais: interação e modalidade}

Um modo semiótico também pode ser representado em termos de relações entre o produtor de um signo e o receptor daquele signo, ou seja, esse modo semiótico poderá representar uma relação entre o produtor, o expectador e o objeto representado, como é o caso do significado interpessoal. Esse objeto pode ser representado interagindo com o expectador por meio de um olhar, por exemplo, e assim manter um maior ou menor distanciamento social, o que resulta em uma interação entre objeto representado e expectador (KRESS; van LEUWEEN, 2006, p. 43). 
Essas relações de representação e interação entre participantes e expectadores podem ser constituídas de diversas formas, tais como: contato, que pode demandar ou oferecer algo do/para o expectador, por meio do olhar do PR; distância social, que pode ser pessoal, social ou impessoal, dependendo da distância da imagem; perspectiva, que nos mostra o envolvimento dos participantes, ou não, com o expectador; poder, que pode ser do expectador (ângulo alto), igualdade de poder (ângulo na altura dos olhos) ou do PR (ângulo baixo).

A modalidade diz respeito à confiabilidade de uma imagem representada, se ela representa a realidade/verdade por meio das cores, saturação, brilho, agudeza, tamanho, profundidade, representação, contextualização e/ou iluminação. A modalidade é interpessoal e não ideacional, porque não expressa verdades ou mentiras absolutas, mas produz verdades compartilhadas ao aproximar os leitores ou ouvintes de algumas afirmações e ao distanciá-los de outras (KRESS; van LEUWEEN, 2006, p.155).

No significado interpessoal o foco é a relação entre PR e expectador, já no significado textual é a disposição das imagens que terá o poder de significação.

\subsection{Significados textuais: composição}

O significado textual em uma imagem é a capacidade que ela tem de formar textos e complexos de signos que sejam coerentes internamente uns com os outros e externamente com o contexto para o qual ela foi produzida. Em imagens, uma diversidade de arranjos faz com que sejam realizados diferentes significados textuais. Elas podem apresentar diferentes valores de informação quando dispostas no centro, à direita, à esquerda, acima ou abaixo (KRESS; van LEUWEEN, 2006, p. 43).

A composição das imagens pode ser realizada da seguinte maneira em relação ao seu posicionamento: 1) em termos do valor da informação: centralizada (tríptica, circular, centro margem, mediador - elementos polarizados); polarizada (dado - novo, polarização nãohorizontal, ideal - real, polarização não-vertical); 2) em termos de saliência (máxima ou mínima saliência); e 3) em termos de enquadramento (máxima ou mínima conexão).

Os três significados, ideacional, interpessoal e textual, são diversas vezes encontrados em um mesmo modo visual. O que poderá acontecer é o predomínio de uma representação sobre a outra. A soma dos significados nas imagens das páginas introdutórias da unidade 1 do Prime 1 será o foco da análise, o que poderá esclarecer o papel desempenhado pela 
combinação das imagens nessas páginas e que informações elas nos trazem, além de ilustrar o conteúdo a ser trabalhado nas unidades do livro.

\section{Metodologia}

A coleção Prime foi publicada em 2010 pela editora MACMILLAN do Brasil e elaborada por três autoras brasileiras ${ }^{4}$. A obra é composta por três volumes com doze unidades cada um. Cada LD da coleção tem quinze seções e tem como foco o ensino de ILE para o ensino médio, com unidades constituídas por diferentes gêneros discursivos de PC como foco de análise e de ensino da linguagem. Cada página introdutória das unidades contém entre uma e seis imagens (a maioria fotográficas) que somam um total de 45 imagens nas páginas introdutórias do LD. O corpus da presente análise limitar-se-á a página introdutória de uma unidade (Figura 1) do $\mathrm{LD}$, devido ao curto espaço para descrição da pesquisa.

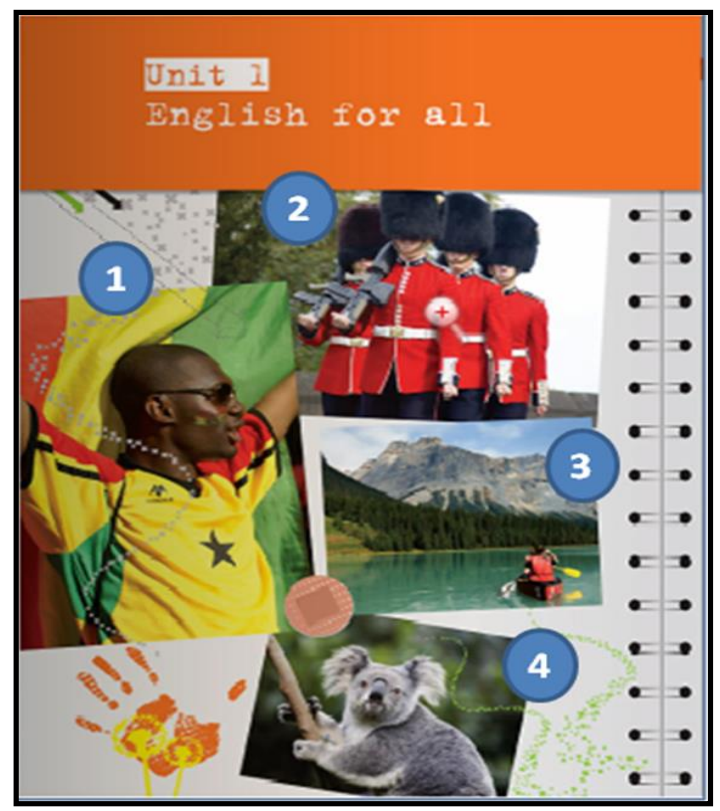

Figura 1 - Página Introdutória da Unidade 1 (Prime 1)

Para que se chegasse aos significados descritos anteriormente, segundo a gramática visual (KRESS; van LEUWEEN, 2006), parti da análise da página introdutória da unidade do

\footnotetext{
${ }^{4}$ Reinildes Dias é Ph. D. em Tecnologia Educacional pela Concórdia University de Montreal, mestre pela Universidade Federal de Minas Gerais (UFMG) e Professor Adjunto da mesma universidade; Leina Jucá é Mestre em Linguística Aplicada ao Ensino de Línguas Estrangeiras, licenciada em Letras pela UFMG e Professora Assistente da Universidade Federal de Ouro Preto; e Raquel Faria é Mestre em Linguística Aplicada, licenciada em Letras pela UFMG e Professor Temporário da Universidade Federal de Lavras. 
LD, considerando a linguagem não verbal (imagens) e a linguagem verbal (título da unidade). As imagens dessa página são fotográficas e, portanto, naturalistas, do ponto de vista da modalidade. Elas foram numeradas, analisadas e classificadas como um todo, conforme as categorias dos significados ideacional, interpessoal e textual. Em seguida, foram analisadas de acordo com sua disposição na página, isoladamente.

\section{RESUltados E DisCUSSÃo}

As imagens analisadas são fotográficas e apresentam alto grau de modalidade, o que faz com que o leitor/aluno identifique-se mais com a imagem representada e confira-lhe um alto grau de confiabilidade e realidade. Para Motta-Roth e Hendges (2010, citando KRESS e van LEUWEEN, 2006, p. 50) em imagens naturalísticas de cunho fotográfico, como é o caso da maioria das páginas introdutórias do Prime 1, há sempre uma grande "abundância de detalhes" que podem ser descritos como processos conceituais analíticos, ou seja, os participantes são representados em sua essência. No caso das imagens da unidade 1 os PRs estão representando seus países/continentes de origem. Esse tipo de processo relaciona os participantes em termos de uma estrutura parte-todo, como a Figura 1 que traz detalhes das cores, roupas e expressão facial dos PRs.

A maioria das imagens nas doze páginas introdutórias está relacionada ao título da unidade, e o que sugere um convite ao leitor/aluno a interagir com aquele mundo representado e, ao mesmo tempo, com os PRs, por meio de uma ferramenta de poder: a língua inglesa. Essa relação das imagens com o título ganha destaque por meio dos significados ideacionais simbólicos e representacionais analíticos, uma vez que se destacam atributos dos PRs levando o leitor/aluno a reconhecer os países representados na página introdutória. Além disso, as imagens antecipam o assunto da unidade ao estarem relacionadas com a linguagem verbal, "English for all”, mesmo que de forma ambígua, além de enfatizar a importância da língua inglesa como hegemônica.

Como sugere Kress (2010, p.142), a página de um LD não é mais formada somente pelo texto escrito, mas tornou-se uma unidade semiótica de significado. O autor aponta que o LD sofreu muitas mudanças visuais e de conteúdo ao longo do último século, uma vez que a sociedade, o currículo e a pedagogia sofreram mudanças. Ele explica que os LDs contemporâneos apresentam a cultura popular e os alunos são chamados a interagir com o material, não individualmente, mas discutindo questões polêmicas em grupo. 
No que se refere à produção desses materiais, deve-se levar em conta que o produtor toma como ponto de partida o uso de recursos que façam sentido para determinados propósitos educacionais. Nessa categoria de “produtor de LD" há outros participantes envolvidos, como o escritor, o desenhista, o editor, o compositor, dentre outros profissionais (KRESS, 2010, p.142). Na teoria da comunicação contemporânea há a necessidade de uma abordagem retórica onde a figura do retor na formulação da mensagem é essencial. $\mathrm{O}$ retor avalia os aspectos da situação comunicativa dependendo das características da audiência e, em seguida, o design e a produção dão forma aos interesses do retor e assim tem-se o processo de disseminação das informações (KRESS, 2010, p.26). A escolha das imagens colocadas nas páginas introdutórias do Prime provavelmente segue essas várias etapas de produção até tomarem forma no livro e alcançarem seu objetivo comunicativo, a produção de conhecimento.

Ao analisarmos as imagens da página como um todo, podemos dizer, em termos ideacionais, que elas são conceituais e têm uma classificação encoberta, pois os PRs pertencem a uma mesma categoria: representam países falantes de língua inglesa de vários continentes. Podemos sugerir, ainda, que a disposição das imagens, conforme o significado textual, realiza-se com a disposição em forma mediana, uma vez que o centro forma uma ponte entre dado e novo, bem como entre real e ideal, conciliando elementos polarizados. O que mais chama a atenção em relação ao significado composicional das imagens é o posicionamento da Imagem 2, representando o poder, a hegemonia do inglês, disposta bem acima, como o ideal. Nas Imagens 1, 3 e 4 há um enquadramento; elas estão conectadas por um círculo adesivo ou band-aid e parecem convergir para a imagem do topo. O homem ganense na Imagem 1 olha para o lado direito da página, o coala da Austrália que está bem abaixo e o esportista da Nova Zelândia, remando em direção as montanhas, parecem levar do real para o caminho do ideal, ou seja, o inglês padrão da Inglaterra. Toda essa disposição dos elementos na página leva o aluno/leitor a pensar que há um inglês ideal, mas o título da unidade "English for all" parece ambíguo: é um inglês para todos ou se quer representar os países onde o inglês é a língua nativa? Por que não há imagens de outras etnias como a brasileira? As imagens ilustram os lugares onde o inglês é a língua materna, não havendo possibilidade de outras culturas também aprenderem esse idioma? Deste modo somos levados a pensar que por meio do inglês podemos alcançar o que parece inatingível e chegar a um padrão de vida/comportamento ideal. 
O significado ideacional da Imagem 1 se dá por meio da representação conceitual simbólica atributiva, uma vez que a estrela e as cores da bandeira fazem com que o leitor possa inferir o país de origem (Gana) do PR na foto. Por outro lado, a Imagem 1 também traz a representação narrativa pois o PR parece olhar para um lugar que o leitor desconhece e assim temos a reação não-transacional, uma vez que há um ator mas não uma meta. $\mathrm{O} P R$ na imagem se relaciona com o título da unidade na medida em que representa uma etnia, um país diferente daquele para o qual o LD é destinado, ou seja, o Brasil. O aluno/leitor aciona seu conhecimento prévio e curiosidade sobre o país de origem da bandeira e outros países que tenham essas mesmas cores na bandeira, como é o caso do Brasil. O ângulo oblíquo na Imagem 1 nos remete ao significado interpessoal e um não envolvimento do PR com o expectador que não pertence ao mesmo país do leitor/aluno para o qual o livro é destinado. Porém, a relação com as cores da nossa bandeira pode ser um meio que o LD encontra de fazer com que o aluno se identifique com o participante, uma vez que as cores predominantes são o verde e o amarelo. Além disso, o PR de Gana representa um falante do inglês britânico já que o país já foi uma colônia do Reino Unido. O significado textual dessa imagem pode ser compreendido na relação dado-novo, uma vez que o lado esquerdo da imagem representa o dado, enquanto que o lado direito, para onde o PR direciona seu olhar, representa o novo.

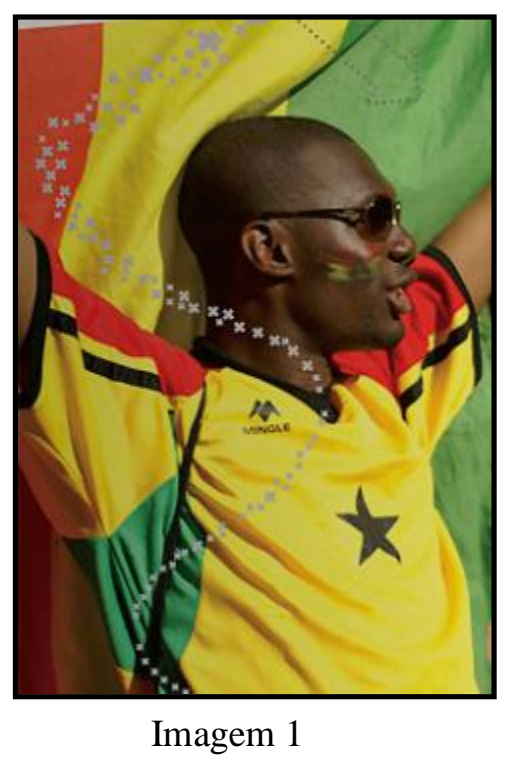

$\mathrm{Na}$ Imagem 2, temos o significado ideacional realizado pela representação de guardas britânicos com suas vestes características; chapéu, cor e estilo da roupa que conferem à imagem um atributo simbólico: componentes da vestimenta típica de um guarda inglês. Pode- 
se também dizer que eles estão alinhados de forma classificatória, pois pertencem à mesma categoria, representados por uma taxonomia encoberta, uma vez que não há uma hierarquia, todos pertencem à mesma classe e, possivelmente, têm as mesmas condições financeiras e sociais, além de falarem o inglês britânico. No que se refere ao significado interpessoal o ângulo baixo, de onde a foto foi tirada, representa o poder dos PRs em relação ao expectador.

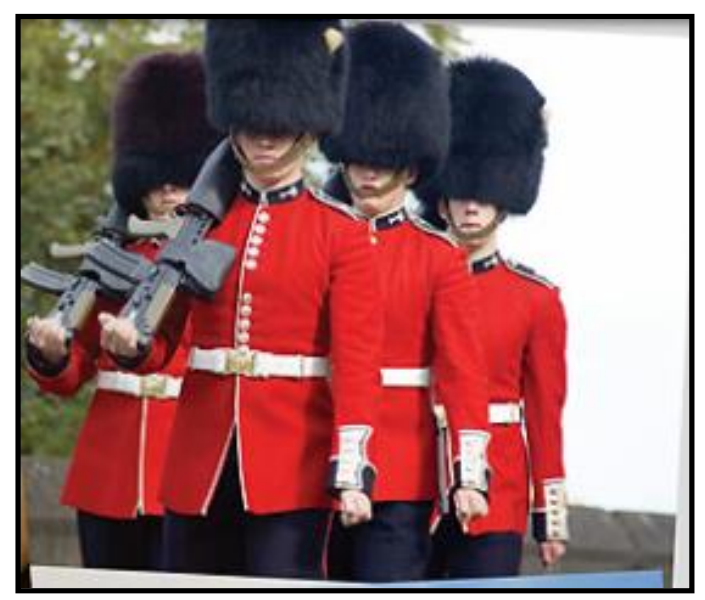

Imagem 2

O significado ideacional da Imagem 3 é representado por meio do atributo simbólico, pois representa mais um lugar onde a língua inglesa é falada, A Nova Zelândia, com suas montanhas e paisagem típicas. Em relação ao significado interpessoal, a imagem parece mostrar um não envolvimento do(s) PR(s) com o expectador, uma vez que ele(s) está (ão) de costas. O significado textual se dá por meio da relação ideal, montanhas perto do céu, e real, na água.

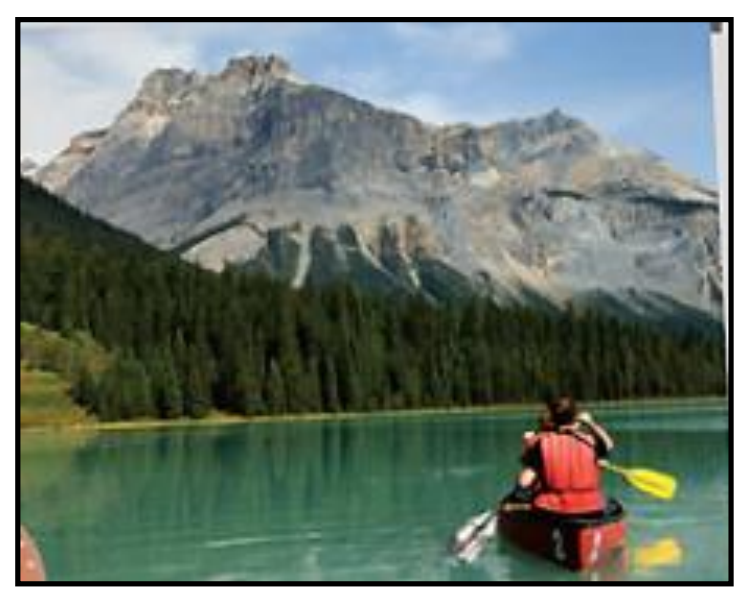

Imagem 3 
A Imagem 4, do coala, é representada por meio do significado interpessoal na medida em que o PR interage e demanda algo do leitor. Essa demanda pode ser entendida como um chamado para que o leitor/aluno interaja com ele, mostrando que, apesar de não termos essa espécie no Brasil, ela pertence a um determinado lugar, Austrália, onde as pessoas também falam a língua inglesa. Desse modo, temos também o significado ideacional com a representação conceitual analítica e simbólico atributiva, uma vez que a imagem simboliza um animal típico da Austrália. Já o significado textual da imagem é representado por meio da saliência do PR, o coala, que fica em primeiro plano e legível, e em segundo plano está o cenário, não tão importante e que, por isso, não recebe destaque na imagem.

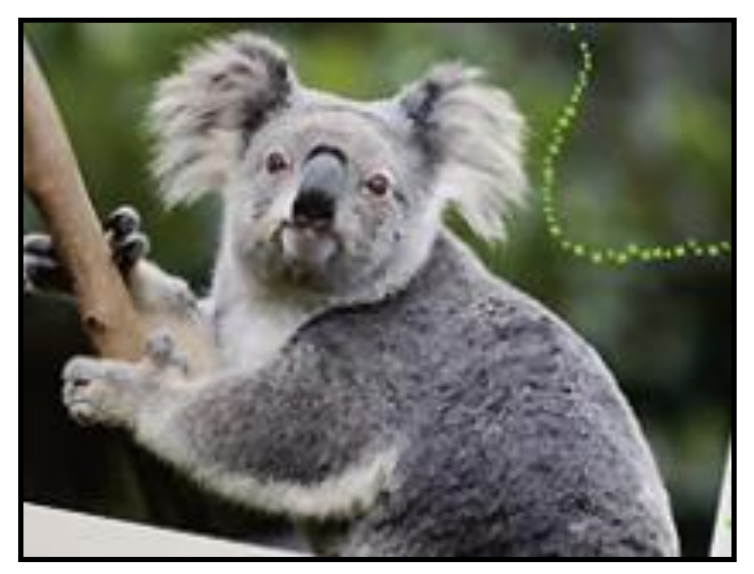

Imagem 4

O que podemos considerar nessa análise é o destaque para o significado ideacional com os atributos simbólicos dos PRs, que nos remetem ao país de origem de cada um e a língua nativa desses países, a Língua Inglesa.

\section{CONSIDERAÇÕES FINAIS}

Neste trabalho, foi proposta uma discussão sobre a relação entre a linguagem verbal e não verbal estabelecida na página introdutória da unidade 1 do LD de ILE, Prime 1. A relação encontrada entre esses dois modos semióticos, verbal e não verbal, pode ter como principal propósito a busca pela atenção do aluno, despertando curiosidade a respeito dos temas que serão tratados na unidade e antecipando o assunto que será discutido. O significado da linguagem verbal, English for all, parece ambíguo em relação à linguagem não verbal, pois não sabemos se sugere um inglês para todas as etnias ou se sugere um padrão de inglês: aquele falado nos países representados nas imagens. Sendo assim, as imagens parecem sugerir 
uma visão ideológica sobre um padrão de língua inglesa a ser aprendido: o inglês falado na Inglaterra. Porém, uma análise do LD como um todo ou de toda a coleção Prime de LDs poderia ser aprofundada em estudos futuros a fim de fornecer respostas mais assertivas sobre esse resultado, considerado parcial, tendo em vista o corpus analisado.

Uma das razões para se justificar o estudo sobre as categorias semióticas, presentes nas composições multimodais, e a discussão sobre como a linguagem verbal e a não verbal interagem é a necessidade de se expandir o conjunto de discursos e registros dos leitores/alunos a fim de os ajudar a alcançar propósitos sociais (MOTTA-ROTH; NASCIMENTO, 2009). Isso se dá não só por meio da língua escrita e/ou falada, como muitos materiais sugerem, mas também por meio de formas imagéticas, gestos, sons e outros modos semióticos capazes de fazer o aluno agir no mundo contemporâneo. Formar leitores críticos que deem conta de interpretar textos multimodais parece ser uma necessidade da contemporaneidade.

Recebido em: março de2016 Aprovado em: outubro de 2016 arianerossi@yahoo.com.br

\section{Referências}

DIAS, D.; JUCÁ, L.; FARIA, R. Prime: inglês para o ensino médio. São Paulo: Macmillan do Brasil, 2009.

KRESS, G. Multimodality: a social semiotic approach to contemporary communication. London/New York: Routledge, 2010.

KRESS, G. VAN LEEUWEN. Reading images: the grammar of visual design. London; New York: Routledge, 2006 [1996].

MOTTA-ROTH, D. Questões de metodologia em análise de gênero. In: KARWOSKI, A. M.; GAYDECZKA, B.; BRITO, K. S. (Orgs.). Gêneros textuais: reflexões e ensino. 2. Ed. Rev. Aument. Rio de Janeiro: Lucerna, 2006. p. 145-163.

MOTTA-ROTH. D; HENDGES. G. R. Explorando modalidades retóricas sob a perspectiva da multimodalidade. Letras (UFSM), 2010, vol. 20 (40), p. 43-66.

MOTTA-ROTH, D.; NASCIMENTO. F. S. Transitivity in visual grammar: concepts and applications. Linguagem \& Ensino (UCPel), 2009, vol.12 (2), p. 319-349. 